\title{
KARAKTERISTIK MIKROPLASTIK PADA EKOSISTEM PESISIR DI KAWASAN MANGROVE PERANCAK, BALI
}

\author{
Agung Yunanto ${ }^{a}, *$, Nazulatul Fitriah ${ }^{\mathrm{a}}$ dan Nuryani Widagti ${ }^{\mathrm{a}}$

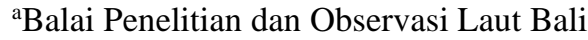 \\ *Koresponden penulis (Alamat email) : ag.yunanto@gmail.com
}

\begin{abstract}
Abstrak
Tingkat pencemaran mikroplastik di kawasan ekosistem pesisir telah diteliti pada bulan Juli 2016. Penelitian bertujuan untuk mengetahui tingkat pencemaran mikroplastik pada daerah hutan alami dan area bekas tambak di kawasan hutan mangrove Perancak Jembrana Bali. Pengambilan sampel sedimen dilakukan dengan corer dengan kedalamam 0-30 cm, yang selanjutnya akan dibagi dalam tiga tingkat kedalaman $(0-10 \mathrm{~cm}, 10-20 \mathrm{~cm}$ dan $20-30 \mathrm{~cm})$. Metode pemisahan partikel mikroplastik $(0,25-5 \mathrm{~mm})$ didasarkan pada pemisahan berat jenis. Hasil penelitian menunjukkan jenis mikroplastik yang ditemukan pada daerah hutan alami dan bekas tambak adalah film, fiber, fragmen dan pelet. Daerah hutan alami (F) ditemukan persentase tertinggi mikroplastik adalah dari jenis film $(82,2 \%)$, kemudian diikuti dengan fragmen $(9,7 \%)$ fiber $(5,8 \%)$ dan pelet $(2,3 \%)$. Bekas tambak $(\mathrm{P})$ ditemukan dominasi mikroplastik yang sama yaitu film $(48,5 \%)$ diikuti fragmen $(31,6 \%)$, fiber $(17,7 \%)$ dan pelet $(2,2 \%)$. Kelimpahan jenis mikroplastik di daerah hutan alami lebih besar dibandingkan areal bekas tambak. Kondisi ini mengindikasikan bahwa hutan alami lebih efektif dalam menjebak sampah plastik dibanding dengan bekas tambak.
\end{abstract}

Kata kunci: mangrove, mikroplastik, Perancak, sedimen, bekas tambak

\begin{abstract}
The level of microplastic pollution in the coastal ecosystem area was studied in July 2016. This study aimed to determine the level of microplastic pollution in natural forest areas and ex-pond areas in the mangrove forest area of Perancak Jembrana Bali. Sediment sampling is carried out with a corer with a depth of 0-30 $\mathrm{cm}$, which will then be divided into three levels of depth $(0-10 \mathrm{~cm}, 10-20 \mathrm{~cm}$, and 20-30 cm). The microplastic particle separation method $(0.25-5 \mathrm{~mm})$ is based on the separation of specific gravity. The results showed that the types of microplastics found in natural forest areas and former ponds were a film, fiber, fragments, and pellets. The natural forest area $(\mathrm{F})$ found that the highest percentage of microplastics was from the type of film $(82.2 \%)$, followed by fragments $(9.7 \%)$ fiber $(5.8 \%)$, and pellets $(2.3 \%)$. The pond scars $(\mathrm{P})$ were found to be the same predominance of microplastics, namely film (48.5\%) followed by fragments $(31.6 \%)$, fiber $(17.7 \%)$, and pellets $(2.2 \%)$. The abundance of microplastic species in natural forest areas is greater than in ex-pond areas. This condition indicates that natural forests are more effective in trapping plastic waste than abandon ponds.
\end{abstract}

Keywords: mangrove, microplastic, Perancak, sediment, abandon pond

\section{PENDAHULUAN}

Penggunaan plastik di dunia dan secara khusus di Indonesia dari tahun ke tahun semakin meningkat yang mengakibatkan semakin meningkat pula potensi bahaya limbah plastik bagi lingkungan. Potensi bahaya limbah plastik ini disebabkan oleh sifat dari plastik yang sulit terurai secara alami karena merupakan produk polimerisasi minyak bumi dengan ikatan kimia yang kuat dan sulit untuk diuraikan. Sampah plastik dapat terdegradasi menjadi mikroplastik yang dapat terapung di lautan dan berbahaya bagi kehidupan biota laut. Mikroplastik merupakan partikel plastik berukuran lebih kecil dari 5,0 mm [1] . Ukurannya yang kecil ini dapat menyerupai plankton yang menjadi sumber makanan biota laut dari yang kecil hingga biota berukuran besar dalam siklus 
rantai makanan di laut dan akhirnya menjadi produk olahan hasil laut yang dikonsumsi oleh manusia.

Wilayah Indonesia sebagian besar terdiri dari kepulauan dengan bagian terpenting adalah wilayah pantai dan pesisir dengan garis pantai sepanjang $81.000 \mathrm{~km}$. Dengan demikian Indonesia berpotensi besar menjadi kontributor sampah laut di dunia. Hasil penelitian menunjukkan, Indonesia merupakan negara terbesar kedua setelah China yang menghasilkan sampah plastik ke lautan yaitu sebanyak 3,53 juta metrik ton per tahun [2] .

Salah satu ekosistem utama pendukung kehidupan pada wilayah pesisir dan kelautan adalah ekosistem hutan mangrove yang mempunyai fungsi ekologis dan fungsi ekonomis. Salah satunya yaitu sebagai penyerap limbah, termasuk di dalamnya yaitu limbah mikroplastik. Hutan mangrove Perancak, Jembrana Bali merupakan hutan yang terdiri dari hutan alami dan hutan yang mengalami restorasi karena sebelumnya adalah areal tambak. Saat ini, hutan tersebut juga menjadi salah satu stasiun monitoring permanen untuk mengetahui kemampuan mangrove dalam beradaptasi terhadap kenaikan muka laut [3].

Secara fisik terlihat keberadaan sampah plastik di areal mangrove, baik yang berasal dari hanyutan dari sungai ataupun dari aktivitas pembuangan sampah secara liar. Hal ini dapat mengakibatkan penumpukan sampah plastik di hutan mangrove yang berakibat pada pencemaran lingkungan dan penurunan nilai estetika hutan mangrove. Sebagai daerah yang dinamis dan dipengaruhi oleh pasang surut, keberadaan sampah plastik akan tersebar ke seluruh areal hutan mangrove. Akar mangrove dan proses proses alami lainnya akan meningkatkan mekanisme terperangkapnya plastik dalam sedimen. Proses tersebut juga akan mendegradasi plastik menjadi berukuran lebih kecil, hingga berukuran mikro atau biasa disebut dengan mikroplastik. Dengan demikian perlu dilakukan penelitian berkelanjutan mengenai tingkat pencemaran, potensi dan dampak limbah mikroplastik serta upaya-upaya yang dapat dilakukan untuk kualitas lingkungan hidup.

\section{METODE PENELITIAN}

Penelitian mengenai pencemaran mikroplastik dilakukan pada bulan Juli 2016 di kawasan mangrove Perancak, Jembrana Bali. Lokasi pengambilan sampel sedimen ada empat titik pada dua daerah yang berbeda yaitu dua titik kawasan hutan alami mangrove (F) dan dua titik daerah bekas tambak (P) yang sudah menjadi areal mangrove (Gambar 1). Proses analisis mikroplastik dilakukan di Laboratorium Kualitas Perairan, Balai Penelititan dan Observasi Laut Bali. 


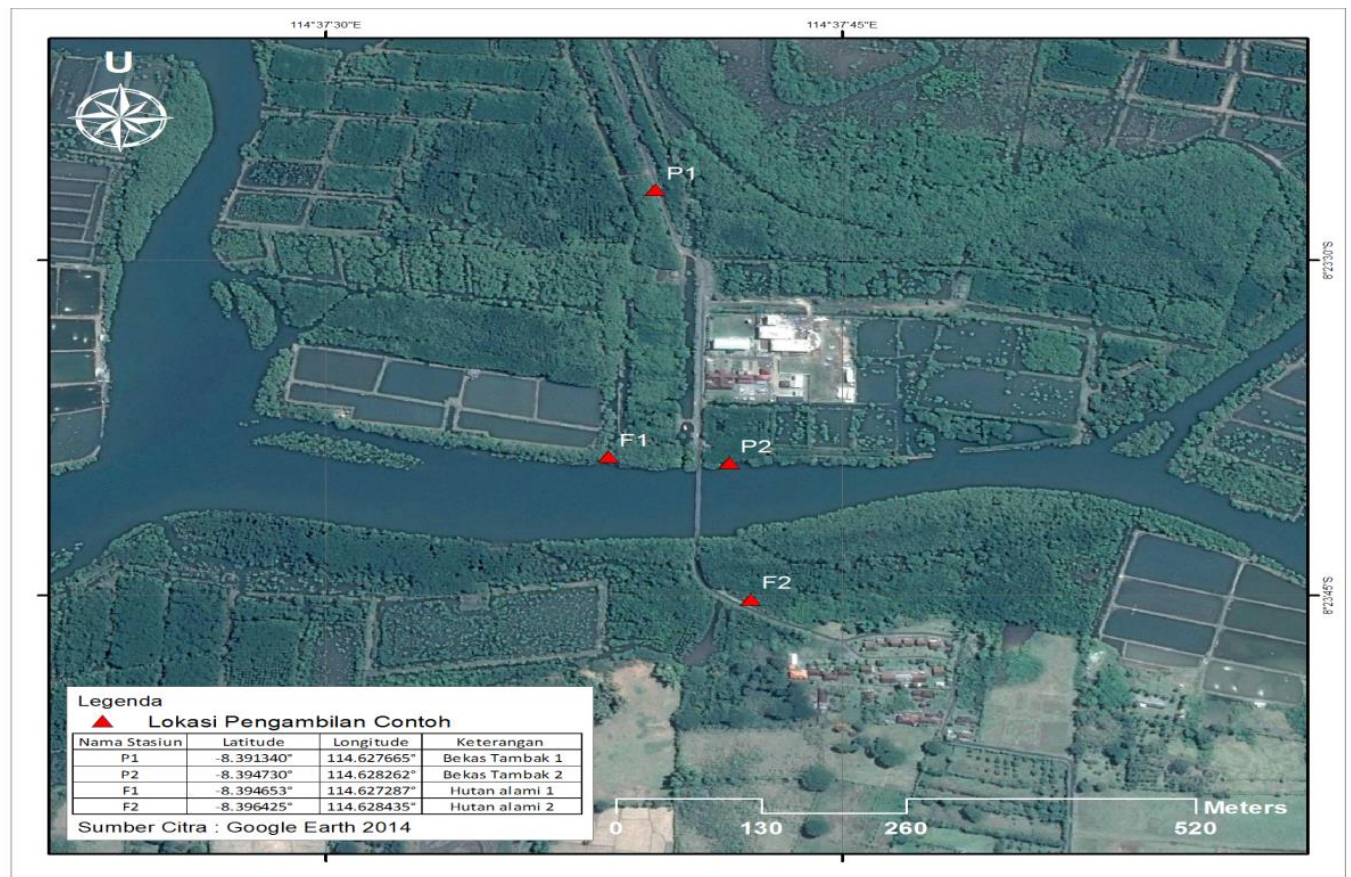

Gambar 1. Peta Lokasi Titik Pengambilan Sampel

Metode purposive sampling digunakan dalam pemilihan titik sampel yaitu pemilihan titik secara sengaja sesuai persyaratan (karakteristik, sifat-sifat, kriteria dan ciri) sampel. Titik koordinat ditentukan dengan menggunakan alat penerima GPS (Global Positioning System).

Tabel 1. Titik Koordinat Pengambilan Sampel

\begin{tabular}{cclll}
\hline No & Nama Stasiun & Lintang & Bujur & Keterangan \\
\hline 1. & F1 & $-8.394653^{\circ}$ & $114.627287^{\circ}$ & Hutan alami 1 \\
2. & F2 & $-8.396425^{\circ}$ & $114.628435^{\circ}$ & Hutan alami 2 \\
3. & P1 & $-8.391340^{\circ}$ & $114.627665^{\circ}$ & Bekas Tambak 1 \\
4 & P2 & $-8.394730^{\circ}$ & $114.628262^{\circ}$ & Bekas Tambak 2 \\
\hline
\end{tabular}

Pengambilan sampel dilakukan dengan corer menggunakan pipa paralon berdiameter $7,5 \mathrm{~cm}$ berdasarkan tiga tingkat kedalaman $(0-10 ; 10-20 ; 20-30 \mathrm{~cm})$. Metode perolehan mikroplastik $(0,25-5 \mathrm{~mm})$ dari sampel sedimen menggunakan metode pemisahan berdasarkan berat jenis (densitas). Adapun tahapan pemisahan mikroplastik (Gambar 2) terdiri dari (1) preparasi sampel, (2) pemisahan densitas I, (3) proses WPO (wet peroxide oxidation), (4) pemisahan densitas II, (5) pengamatan visual [4]. Tahap preparasi sampel meliputi penimbangan sedimen basah, pengeringan sedimen $\left(90^{\circ} \mathrm{C}, 72 \mathrm{jam}\right)$ dan penimbangan sedimen kering. Tahap pemisahan densitas I dengan menggunakan larutan $\mathrm{NaCl}$ jenuh (5M). Sebelum penambahan $\mathrm{NaCl}$ jenuh dilakukan penyaringan menggunakan saringan $5 \mathrm{~mm}$. Proses pengadukan setelah penambahan $\mathrm{NaCl}$ jenuh akan mempercepat terbentuk sedimen terapung yang kemudian dilakukan penyaringan menggunakan sieve $0,25 \mathrm{~mm}$. Padatan yang terkumpul pada sieve dilakukan pengeringan dengan oven $\left(90^{\circ} \mathrm{C}, 24 \mathrm{jam}\right.$ atau sampai kering). Padatan yang diperoleh kemudian dilakukan penimbangan sehingga dapat diketahui berat total mikroplastik dan material alami. Tahapan berikutnya yaitu proses

WPO (wet peroxide oxidation). WPO merupakan larutan campuran yang terdiri dari larutan $\mathrm{H}_{2} \mathrm{O}_{2} 30 \%$ dan larutan $\mathrm{FeSO}_{4} .7 \mathrm{H}_{2} \mathrm{O}$ $0,05 \mathrm{M}$ yang bertindak sebagai katalisator. 
Penggunaan larutan WPO ditujukan untuk mencerna material organik labil sehingga mempermudah analisis mikroplastik. Tahap pemisahan densitas II menggunakan density separator. Partikel yang mengapung dari hasil pemisahan ini dikeringkan selama 24 jam kemudian dilakukan pengamatan secara visual menggunakan mikroskop dengan perbesaran 10x. Kemudian dilakukan penimbangan berat mikroplastik. Data yang diambil adalah kelimpahan dalam partikel $/ \mathrm{kg}$ sedimen kering [5] dan dilakukan pengolahan data dengan Microsoft excel. Selain itu ditentukan komposisi jenis mikroplastik yang ditemukan dalam persen (\%) pada kedua kawasan yaitu hutan mangrove alami dan mangrove bekas tambak.

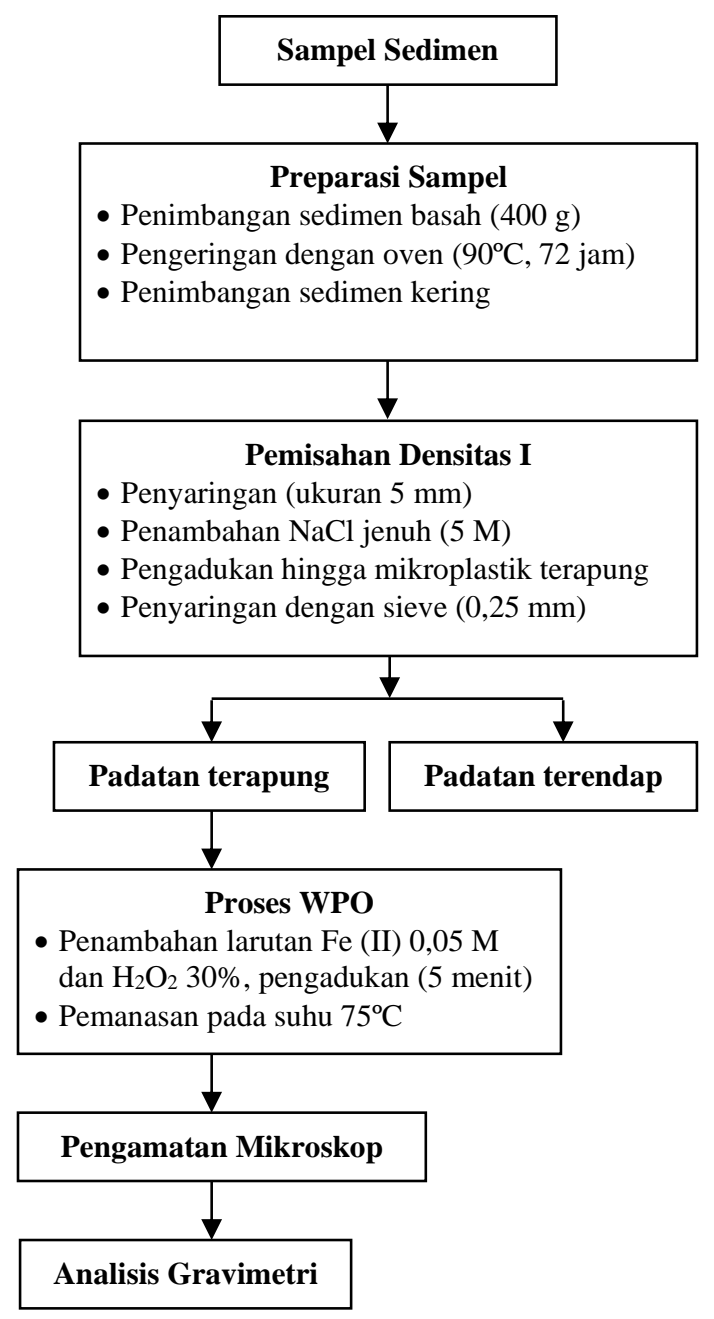

Gambar 2. Diagram Alir Analisis Mikroplastik (NOAA, 2015 dengan modifikasi)

\section{HASIL DAN PEMBAHASAN}

\section{Kondisi umum}

Desa Perancak merupakan salah satu dari 22 desa di Kecamatan Negara, Kabupaten Daerah Tingkat II, Jembrana. Desa tersebut terbentang di pesisir Samudra Indonesia. Hutan mangrove Perancak, Jembrana Bali terdiri dari mangrove yang tumbuh secara alami dan hasil program penanaman mangrove (restorasi) [3]. Restorasi tersebut dilakukan dengan beralihnya kawasan lahan budidaya tambak menjadi suatu kawasan riset terapan dan observasi kelautan. Karakteristik kedua kawasan tersebut memiliki perbedaan. Berdasarkan hasil riset yang telah dilakukan [3], terdapat 20 spesies mangrove sejati (true mangrove) di kawasan hutan mangrove Perancak Bali. Pada hutan mangrove alami (F) didominasi oleh jenis Avicennia sp. dan Sonneratia alba. Sedangkan pada mangrove bekas tambak (P) didominasi oleh Rhizophora sp. Secara fisik, kawasan hutan mangrove alami terletak lebih dekat dengan aliran sungai yang dekat dengan muara, sedangkan areal mangrove bekas tambak lebih tertutup dan agak jauh dari sungai.

\section{Distribusi Vertikal}

Kelimpahan mikroplastik yang diperoleh dari kawasan hutan mangrove alami (F) dan mangrove bekas tambak (P) memiliki perbedaan karakteristik. Namun dari jenis mikroplastik yang diperoleh memiliki kesamaan. Jenis mikroplastik yang ditemukan pada dua kawasan hutan mangrove Perancak adalah film, fiber, fragmen dan pelet (Gambar 3). Adapun kelimpahan jenis mikroplastik yang ditemukan di hutan mangrove alami (F) dan mangrove bekas tambak (P) Perancak ditunjukkan pada Tabel 2. 

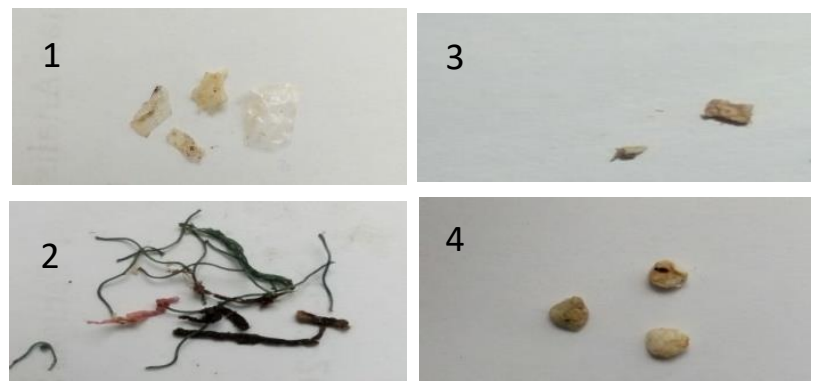

Gambar 3. (1) Film, (2) Fiber, (3) Fragmen, (4) Pelet

Tabel 2. Kelimpahan Jenis Mikroplastik Perancak

\begin{tabular}{|c|c|c|c|c|}
\hline \multirow{2}{*}{ Kode Sampel } & \multicolumn{4}{|c|}{ Kelimpahan Jenis Mikroplastik (partikel/kg sedimen kering) } \\
\hline & Film & Fiber & Fragmen & Pelet \\
\hline F1 0-10 & 53,841 & 10,768 & 25,126 & 10,768 \\
\hline F1 10-20 & 6,402 & 16,005 & 19,206 & 0,000 \\
\hline F1 20-30 & 184,911 & 0,000 & 0,000 & 0,000 \\
\hline F2 0-10 & 59,477 & 0,000 & 0,000 & 0,000 \\
\hline F2 10-20 & 51,370 & 0,000 & 0,000 & 0,000 \\
\hline F2 20-30 & 21,337 & 0,000 & 0,000 & 0,000 \\
\hline P1 0-10 & 8,019 & 12,029 & 20,048 & 0,000 \\
\hline P1 10-20 & 15,106 & 0,000 & 11,329 & 0,000 \\
\hline P1 20-30 & 0,000 & 18,811 & 3,762 & 0,000 \\
\hline P2 0-10 & 57,781 & 0,000 & 3,852 & 3,852 \\
\hline P2 10-20 & 0,000 & 0,000 & 8,673 & 0,000 \\
\hline P2 20-30 & 3,704 & 0,000 & 7,407 & 0,000 \\
\hline
\end{tabular}

Pada kawasan hutan mangrove alami (F) dan bekas tambak (P) ditemukan dominasi jenis mikroplastik tertinggi yaitu film diikuti dengan fragmen, fiber dan pelet (Gambar 3). Pada hutan mangrove alami ditemukan kelimpahan film berkisar 6,402-184,911 partikel $/ \mathrm{kg}$ sedimen kering; fragmen berkisar 19,206-25,126 partikel/kg; fiber berkisar $16,005-10,768$ partikel/kg dan jenis pelet yang hanya ditemukan di satu titik hutan mangrove alami (F1) sebesar 10,768 partikel/kg sedimen kering. Sedangkan pada mangrove bekas tambak ditemukan kelimpahan film berkisar 3,704-57,781 partikel $/ \mathrm{kg}$ sedimen kering; fragmen berkisar 3,762-20,048 partikel/kg; fiber berkisar $12,029-18,811$ partikel/kg dan pelet juga ditemukan hanya pada satu titik lokasi mangrove bekas tambak sebesar 3,852 partikel $/ \mathrm{kg}$ sedimen kering. Persentase masing-masing jenis mikroplastik pada kedua daerah tersebut ditunjukkan pada Gambar 4 dan 5 .

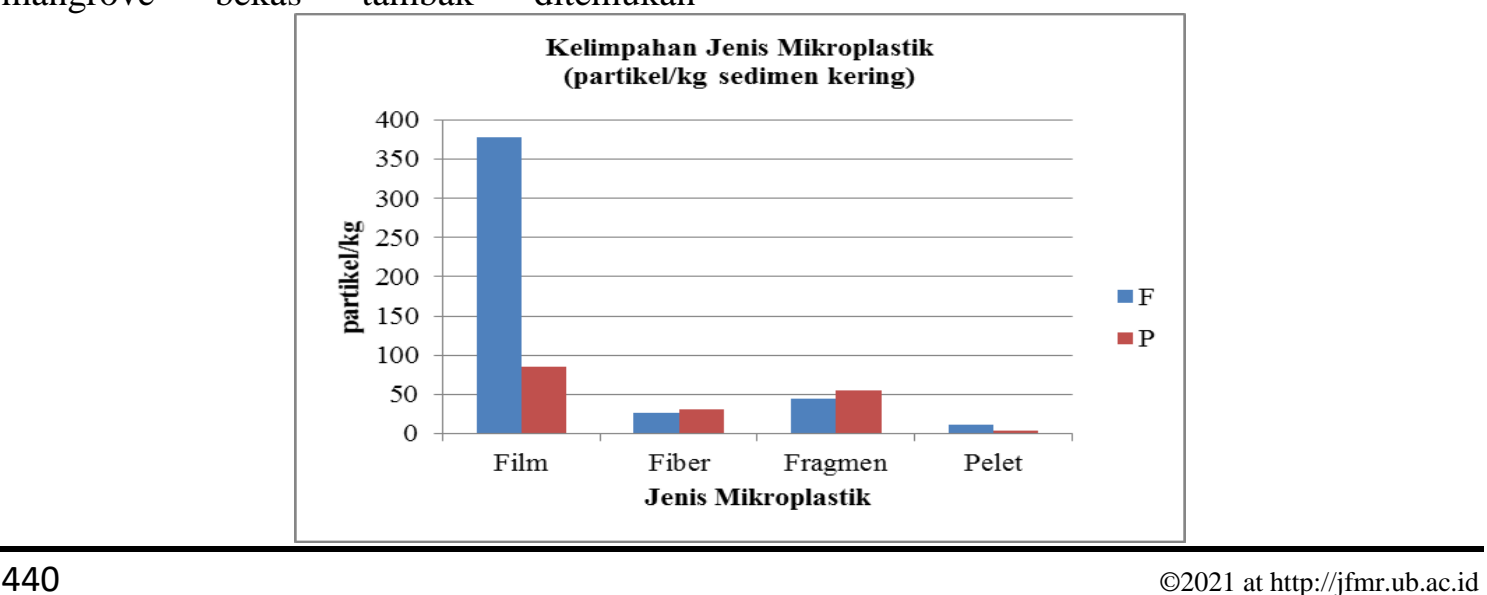


Gambar 4. Kelimpahan Jenis Mikroplastik pada Hutan Mangrove Alami (F) dan bekas tambak (P)

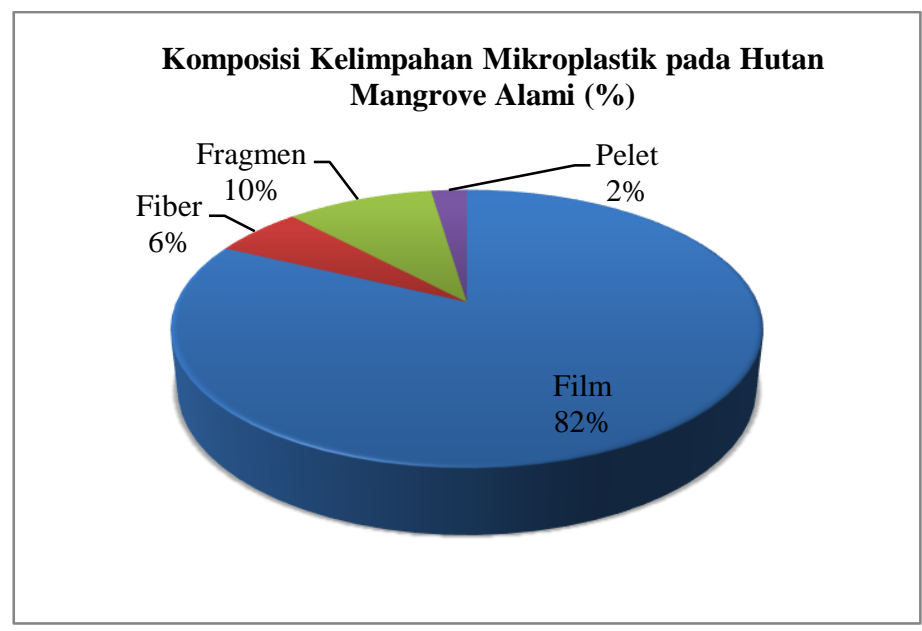

Gambar 5. Komposisi Kelimpahan Mikroplastik pada Hutan Mangrove Alami (F)

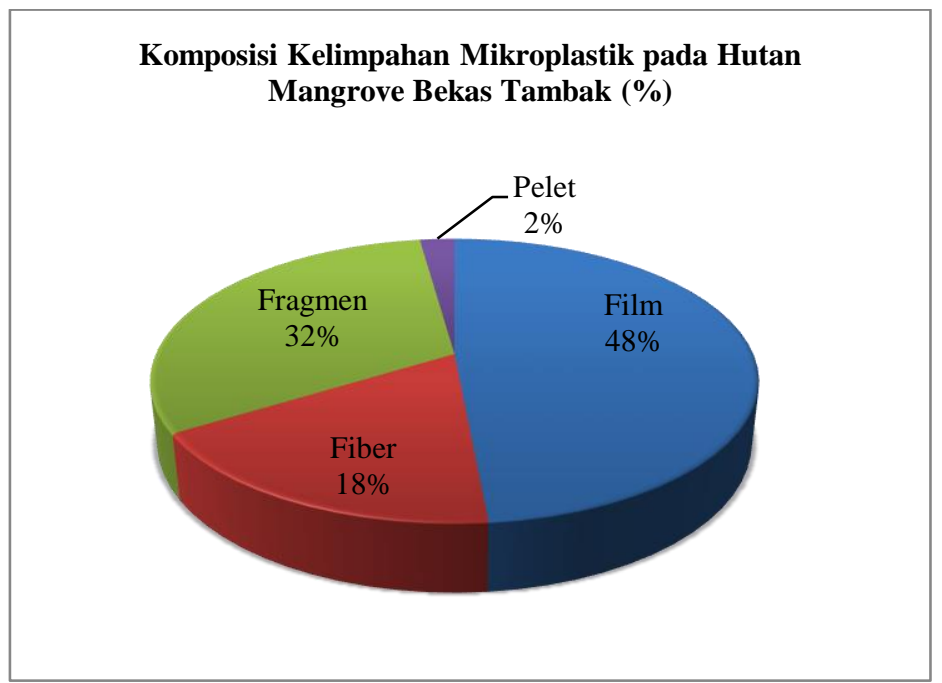

Gambar 6. Komposisi Kelimpahan Mikroplastik pada Hutan Mangrove Bekas Tambak (P)

Dominasi kelimpahan film tertinggi disebabkan oleh densitasnya yang lebih rendah dibandingkan dengan jenis mikroplastik yang lain sehingga lebih mudah ditransportasikan baik oleh udara maupun air. Selain itu mikroplastik jenis film banyak digunakan dalam kehidupan sehari-hari yaitu bersumber dari kantong plastik atau plastik kemasan. Keberadaan fragmen dapat bersumber dari potongan plastik yang tersusun dari ikatan polimer yang sangat kuat. Jenis fiber berasal dari serat-serat tali, kain atau jaring ikan dimana di lokasi pengambilan sampel merupakan tempat penangkapan ikan serta ditemukan pula pembuangan sampah secara liar.
Hutan mangrove alami memiliki kelimpahan film dan pelet lebih tinggi dibandingkan dengan mangrove bekas tambak. Hal ini disebabkan terdapat pembuangan liar sampah rumah tangga berupa kantong plastik dan beberapa jenis sampah plastik yang lain di lokasi hutan mangrove. Sedangkan jenis fragmen dan fiber lebih banyak ditemukan pada mangrove bekas tambak. Pada areal ini lebih sering digunakan untuk penangkapan ikan dan aktivitas lain oleh masyarakat. Selain itu daerah bekas tempat berada di areal lebih tertutup sehingga sampah dengan kuantitas lebih sedikit dibanding sampah yang ditemukan di daerah mangrove alami dapat 
terakumulasi karena jauh dari limpasan air. Namun secara keseluruhan, kelimpahan mikroplastik di kawasan hutan mangrove alami lebih besar jika dibandingkan dengan mangrove bekas tambak (Tabel 3).

Tabel 3. Kelimpahan Total

\begin{tabular}{|c|c|c|}
\hline \multirow[t]{2}{*}{$\begin{array}{l}\text { Jenis } \\
\text { Mikroplastik }\end{array}$} & \multicolumn{2}{|c|}{$\begin{array}{c}\text { Kelimpahan Mikroplastik } \\
\text { (partikel/kg sedimen } \\
\text { kering) }\end{array}$} \\
\hline & $\mathbf{F}$ & $\mathbf{P}$ \\
\hline Film & 377,338 & 84,610 \\
\hline Fiber & 26,773 & 30,840 \\
\hline Fragmen & 44,332 & 55,072 \\
\hline Pelet & 10,76 & 3,852 \\
\hline Jumlah Total & 459,211 & 174,374 \\
\hline
\end{tabular}

\section{Distribusi Horisontal}

Kelimpahan berdasarkan kedalaman menunjukkan pola yang berbeda antar titik dalam satu kawasan (Gambar 7). Pada titik lokasi F1 dan P2 ditemukan pola yang tidak beraturan. Lokasi F1 ditemukan kelimpahan mikroplastik tertinggi pada kedalaman 20-30 cm dengan kelimpahan sebesar 184,911 partikel/kg sedimen kering. Sedangkan pada kedalaman 0-10 $\mathrm{cm}$ diperoleh kelimpahan sebesar 100,503 partikel/kg sedimen kering dan kedalaman 10-20 cm sebesar 41,613 partikel/kg sedimen kering. Pada P2 diperoleh hasil yang berbeda yaitu kelimpahan tertinggi ditemukan pada kedalaman $\quad 0-10 \quad \mathrm{~cm}$ sebesar 65,485 partikel $/ \mathrm{kg}$ sedimen kering, berikutnya kedalaman 20-30 cm sebesar 11,111 dan kedalaman 10-20 cm dengan kelimpahan mikroplastik sebesar 8,673 partikel/kg sedimen kering. Pola kelimpahan mikroplastik yang menarik untuk diamati ditemukan pada titik lokasi F2 dan P1. Lokasi F2 diperoleh kelimpahan mikroplastik pada kedalaman $\quad 0-10 \quad \mathrm{~cm}$ sebesar 59,477 partikel/kg sedimen kering, kedalaman 10-20 $\mathrm{cm}$ sebesar 51,370 partikel/kg sedimen kering dan kedalaman 20-30 cm sebesar 21,337 partikel $/ \mathrm{kg}$ sedimen kering. Sedangkan pada lokasi P1 diperoleh kelimpahan mikroplastik pada kedalaman 0-10 $\mathrm{cm}$ sebesar 40,096 partikel/kg sedimen kering, kedalaman 10-20 $\mathrm{cm}$ sebesar 26,435 partikel/kg sedimen kering dan kedalaman 20-30 cm sebesar 22,573 partikel $/ \mathrm{kg}$ sedimen kering. Berdasarkan hasil tersebut dapat ditemukan pola kelimpahan mikroplastik yang sama dalam tiga tingkat kedalaman pada F2 dan P1 yaitu semakin bertambah kedalaman semakin berkurang kelimpahan mikroplastik. Hal ini terkait dengan laju sedimentasi pada areal penelitian, semakin dalam berarti semakin jauh rentang waktu dan semakin edikit penggunaan plastik oleh masyarakat pada waktu itu. Secara umum kondisi stratifikasi ini serupa dengan penelitian mikroplastik sedimen di Muara Badak [6].

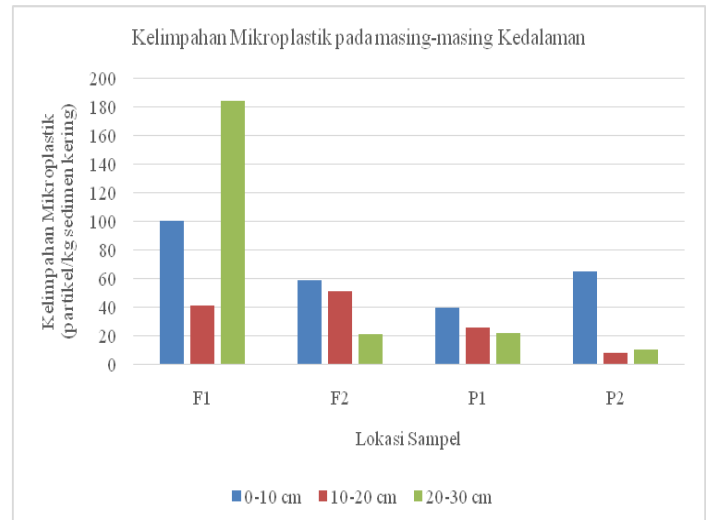

Gambar 7. Kelimpahan Mikroplastik pada Masing-masing Kedalaman Lokasi F dan P

Kelimpahan Mikroplastik pada keempat lokasi dalam kedalaman yang sama menunjukan dominasi jenis mikroplastik yang bervariasi. Pada kedalaman $0-10 \mathrm{~cm}$ ditemukan kelimpahan jenis mikroplastik tertinggi yaitu film pada lokasi F2 yaitu sebesar 59,477 partikel/kg sedimen kering dan terendah ditemukan fragmen dan pelet pada P2 dengan kelimpahan sama sebesar 3,852 partikel/kg sedimen kering (Gambar 8). Dominasi mikroplastik film pada F2 mengindikasikan banyaknya sampah kantong plastik terpapar dan baru terdegradasi pada lapisan atas. Pada akhirnya terjerembab lebih dalam. Sedangkan untuk kelimpahan fragmen dan pelet yang rendah dan hanya ditemukan di titik P2 disebabkan daerah ini lebih tertutup dari limpasan sungai dan juga aktivitas manusia. 


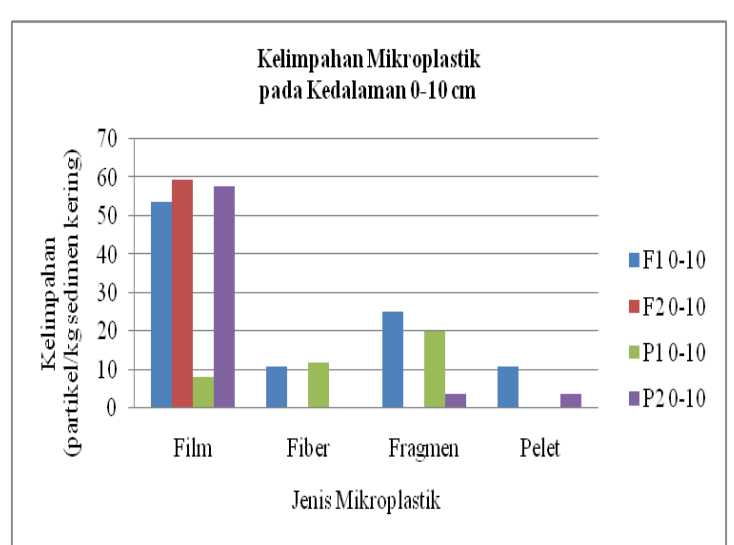

Gambar 8. Kelimpahan Mikroplastik pada Kedalaman 0 $-10 \mathrm{~cm}$

Dominasi mikroplastik yang sama ditemukan pada kedalaman $10-20 \mathrm{~cm}$ yaitu film di titik F2 sebesar 51,370 partikel/kg sedimen kering. Sedangkan terendah ditemukan berupa film pada titik F1 (Gambar 8). Fenomena yang unik ditemukan dominasi kembali jenis mikroplastik berupa film di titik F1 pada kedalaman 20-30 cm (Gambar 9). Hal ini mengindikasikan mikroplastik telah lama terakumulasi dan terfragmentasi menjadi partikel yang lebih kecil. Dengan demikian kelimpahannya menjadi lebih besar. Selain itu, berdasarkan analisis gravimetri diperoleh data lebih rendah dibandingkan pada lapisan 0-10 cm. Jenis terendah yang ditemukan pada kedalaman 20-30 cm berupa film sebesar 3,704 partikel/kg sedimen kering pada titik P2.

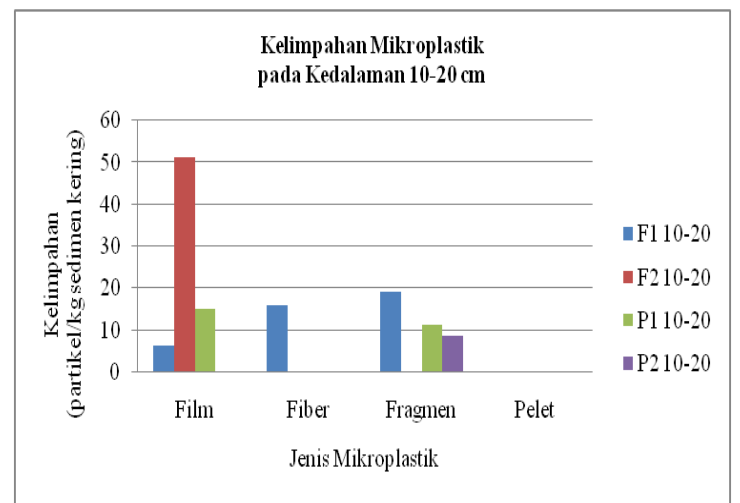

Gambar 8. Kelimpahan Mikroplastik pada Kedalaman 10-20 cm

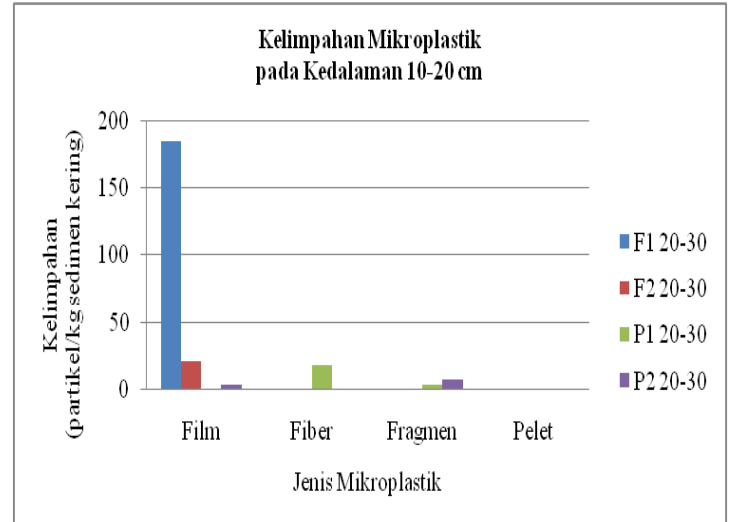

Gambar 9. Kelimpahan Mikroplastik pada Kedalaman 20-30 cm

\section{KESIMPULAN}

Hasil penelitian menunjukkan terdapat perbedaan kelimpahan mikroplastik antara hutan mangrove alami (F) dan mangrove bekas tambak (P). Secara umum, semakin dalam subtrat, semakin sedikit jumlah mikroplastik yang didaparkan Kelimpahan jenis mikroplastik di daerah hutan alami lebih besar dibandingkan areal bekas tambak. Jenis mikroplastik yang ditemukan pada dua daerah tersebut adalah film, fiber, fragmen dan pelet. Daerah hutan alami (F) ditemukan persentase tertinggi mikroplastik adalah dari jenis film $(82,2 \%)$, kemudian diikuti dengan fragmen $(9,7 \%)$ fiber $(5,8 \%)$ dan pelet $(2,3 \%)$. Bekas tambak (P) ditemukan dominasi mikroplastik yang sama yaitu film $(48,5 \%)$ diikuti fragmen $(31,6 \%)$, fiber $(17,7 \%)$ dan pelet $(2,2 \%)$. Kondisi ini mengindikasikan bahwa hutan alami lebih efektif dalam menjebak sampah plastik dibanding dengan bekas tambak.

\section{UCAPAN TERIMA KASIH}

kepada:

Ucapan terima kasih kami sampaikan

1. Balai Penelitian dan Observasi Laut, Bali

2. Tim Laboratorium Kualitas Perairan

3. Semua pihak yang membantu penelitian dan tersusun tulisan ini.

\section{DAFTAR PUSTAKA}

[1] Arthur, C., Baker, J., \& Bamford, H., Eds. Proceedings of the International Research Workshop on the Occurrence, Effects, and 
Fate of Microplastic Marine Debris. Sept 911, 2008. NOAA Technical Memorandum NOS-OR\&R-30, 2009.

[2] Jambeck, J.R., R. Geyer, C. Wilcox, T.R. Siegler, M. Perryman, A. Andrady, R. Narayan, K.L. Law. 2015. Plastic waste inputs from land into the ocean. Science Vol. 347, ISSUE 6223.

[3] Sidik, F., A. Yunanto, N. Widagti, Y. Pancawati, A.W. Hastuti, N.A. Pradisty, H.P. Kadarisman, M.A. Rahman, I.N. Surana, A. Muslim. 2015. "Aplikasi Sistem Observasi Adaptasi Mangrove terhadap Perubahan Iklim”, BPOL, Bali.

[4] Masura, J., J. Baker1, G. Foster,C. Art hur, C. Herring. 2015. "Laboratory Methods for the Analysis of Microplastics in the Marine Environment: Recommendations for quantifying synthetic particles in waters and sediments". NOAA Technical Memorandum NOS-OR\&R-48.

[5] Hidalgo-Ruz V, Gutow L, Thompson RC, Thiel M. 2012. "Microplastics in the marine environment: a review of the methods used for identification and quantification". Environmental Science and Technology. 46:3060- 3075.doi:10.1021/es2031505.

[6] Dewi, I.S., A.A. Budiarsa, I.R. Ritonga. 2015. Distribusi mikroplastik pada sedimen di Muara Badak, Kabupaten Kutai Kartanegara. Jurnal Ilmu Ilmu Perairan, Pesisir dan Perikanan Vol. 4, No. 3. http://jurnal.unsyiah.ac.id/depik/article/view/ 2888/2749. (Diakses 31 Agustus 2016, 20.00 WITA)

http://www.esciencecentral.org/journals/micr oplastics-in-the-marine-environment-currentstatus-assessment-methodologies-impactsand-solutions-2375-4397-1000161.pdf 